\title{
Trabalho e educação no movimento camponês: liberdade ou emancipação?*
}

\author{
Marlene Ribeiro \\ Universidade Federal do Rio Grande do Sul, Faculdade de Educação
}

\section{Introdução}

Abordando o tema "Trabalho, movimentos sociais e educação”, o artigo tem por objetivo trazer elementos para identificar os princípios de liberdade e emancipação - incluindo, em alguns casos, a autonomia - que sustentam as experiências de trabalho-educação em sistema de alternância realizadas pelos movimentos sociais populares rurais/do campo. Tais movimentos compreendem organizações sociais, comunitárias e sindicais que são responsáveis pelas Casas Familiares Rurais (CFRs) e pelas Escolas Famílias Agrícolas (EFAs), tendo por referência, no caso deste estudo, a Federação dos Trabalhadores na Agricultura do Rio Grande do Sul (FETAG/RS). Os movimentos sociais a

* Artigo decorrente dos estudos relacionados aos projetos "Liberdade, autonomia, emancipação na relação trabalho agrícola e educação escolar: conceitos em questão", do qual resulta a obra Movimento camponês, trabalho e educação, encaminhada para publicação, e "Experiências pedagógicas dos movimentos sociais populares e políticas de educação rural/do campo: confronto de concepções (2008-2011)”, ambos com apoio do Conselho Nacional de Desenvolvimento Científico e Tecnológico (CNPq). que nos referimos incluem ainda os integrantes da Via Campesina, que, no Brasil, congrega o Movimento dos Trabalhadores Rurais Sem Terra (MST), o Movimento dos Pequenos Agricultores (MPA), o Movimento dos Atingidos por Barragens (MAB), o Movimento das Mulheres Camponesas (MMC), a Pastoral da Juventude Rural (PJR), a Comissão Pastoral da Terra (CPT) e a Federação dos Estudantes de Agronomia do Brasil (Guzmán \& Molina, 2005, p. 7).

Dentro da Via Campesina, sob a liderança do MST e do MPA, é feita a formação em regime de alternância de trabalho-educação na Fundação de Ensino e Pesquisa da Região Celeiro (FUNDEP) e no Instituto de Capacitação e Pesquisa da Reforma Agrária (ITERRA), ambos no Rio Grande do Sul. Do mesmo modo, a pedagogia em que se alternam tempo-escola e tempo-comunidade é o método adotado pela Escola Nacional Florestan Fernandes (ENFF), criada em 2005, no município de Guararema, estado de São Paulo. Mas nosso estudo aborda somente as experiências realizadas no Rio Grande do Sul. Apesar da diversidade de sujeitos, projetos sociais e formas de organização, todos esses movimentos sociais populares têm em comum uma luta histórica pela terra 
de trabalho, pela democracia e por uma vida digna para todos, o que nos permite sintetizá-los na unidade “movimento camponês".

Considerados - tanto por teorias revolucionárias quanto conservadoras - ignorantes e com formas de organização da produção vistas como arcaicas, os agricultores familiares organizam-se em movimentos sociais populares segundo suas características e demandas, constituindo, como sujeito histórico, o movimento camponês. Este ocupa a cena pública com demandas de reforma agrária, política agrícola e educação do campo e, mais do que isso, cria e administra uma modalidade de educação voltada aos seus interesses, alternando tempos/espaços de trabalho na agricultura, na pecuária e na pesca, com educação na escola. Esse sujeito uno/diverso em construção que ao mesmo tempo se mostra e surpreende, mobilizando órgãos públicos, escolas e universidades para dar respostas às suas demandas, também desperta o interesse dos pesquisadores pelo aprofundamento das questões que emergem de sua caminhada histórica. Eis a importância do estudo, no qual se destaca a necessidade de atentar para o novo contido nas experiências de trabalho-educação dos movimentos sociais populares produzidas à revelia do processo de reprodução e acumulação do capital e do controle do Estado.

A origem e a trajetória das CFRs e das EFAs em vários países da Europa, no Canadá e no Brasil, bem como da FUNDEP e do ITERRA, gerados a partir do MST, no Brasil, têm sido registradas por inúmeros autores, bem como a definição da pedagogia da alternância (Chartier, 1986; Silva; 2003; Estevam, 2003; Bachelard, 1994; Chartier et al., 1997; MST, 2001). O método em que se alternam tempo-comunidade e tempo-escola, adotado pelos cursos oferecidos aos movimentos sociais populares organizados na Via Campesina, não tem o mesmo sentido e história da pedagogia da alternância (ITERRA, 2004).

Neste artigo buscamos captar a liberdade e a emancipação, presentes nas experiências de trabalhoeducação do movimento camponês, como princípios/ fins incorporados nas concepções que sustentam teórica e metodologicamente aquelas experiências. Isso posto, vamos explicitar o entendimento das ideias de liberdade e emancipação em alguns autores clássicos que as formularam. Na sequência, analisaremos as concepções de educação para o trabalho nos autores que orientam as experiências das CFRs e das EFAs, identificadas com as ideias de liberdade seguidas das concepções de trabalho-educação que orientam as experiências da FUNDEP e do ITERRA, identificadas com a perspectiva utópica de emancipação humana.

\section{Liberdade e emancipação: uma leitura dos autores clássicos}

A concepção de liberdade é produzida dentro das práticas que revolucionam o regime feudal no processo de construção do modo capitalista de produção. Nesse processo destaca-se a luta pela liberdade de desenhar e produzir a mercadoria fora dos padrões impostos pelas corporações e de colocá-la à venda em mercados situados para além dos espaços sagrados dos burgos (Polanyi, 2000). Tem como ponto de referência a guerra civil inglesa, ou Revolução Gloriosa de 1688, e entre seus teóricos destacam-se Locke (1973) e Stuart Mill (1998). Para o primeiro, a liberdade do estado de natureza deve ser substituída pela liberdade pactuada que garanta a propriedade da terra baseada no trabalho. Contraditando com essa informação registrada em sua obra, na prática Locke era acionista de uma empresa que comerciava escravos negros (Losurdo, 2006). O segundo, Stuart Mill, reflete sobre a liberdade dirigindo-se às camadas mais civilizadas da população inglesa e apontando para a possibilidade de uma república democrática, com um governo eleito. Chama a atenção para o medo que desperta a "tirania da maioria”, concebida como um coletivo que exerce, ela mesma, o governo (Mill, 1998).

Na França a discussão sobre a liberdade assume uma dimensão política no interior da Revolução Francesa de 1789. Rousseau é o pensador mais expressivo porque relaciona a liberdade a um pacto social assumido por todos. Nesse pacto, cada um dos indivíduos que aí se compromete põe em comum a sua pessoa sob o governo de uma vontade geral. Portanto, da concepção de liberdade ancorada no 
indivíduo proprietário de terras e de bens, formulada por Locke e Mill, a preocupação de Rousseau (1973) desloca-se para a sociedade, de modo que a liberdade de cada um possa preservar o direito de todos a essa mesma liberdade.

Por fim, e tendo consciência dos limites desta síntese, passamos à Alemanha, onde não houve uma revolução propriamente dita, mas o país foi sede da produção do pensamento filosófico mais elaborado de liberdade relacionada à cidadania e ao Estado, representado por Kant e Hegel. Tendo a burguesia - a classe emergente na Alemanha - como o sujeito a quem dirige seu discurso filosófico, Kant (1998a, 1998b) associa a liberdade ao uso da razão esclarecida para o exercício do livre pensar. Quanto à ação, pensa que os súditos devam submeter-se às leis do Estado. Por sua vez, em Hegel (1990) a liberdade é a do espírito que é capaz de refletir sobre si mesmo. Assim, para este filósofo não podem exercer a liberdade os que, para satisfazer suas necessidades de sobrevivência ou decorrentes do estado de natureza, necessitem trabalhar, o que define o privilégio da classe que pensa e que, portanto, tem a liberdade de decidir e agir.

Todavia, esse discurso da filosofia que acabamos de resumir, sendo divorciado da economia e da política, oculta a ação histórica dos camponeses e de trabalhadores urbanos na construção das práticas/concepções de liberdade. Do século XI ao século XVIII, camponeses, religiosos e trabalhadores urbanos promoveram revoltas em países como Inglaterra, França, Alemanha, Rússia, Áustria, Hungria e Suíça. A liberdade de interpretar a Bíblia, pregada por Lutero, é compreendida pelos camponeses como possibilidade de instituir-se a justiça social. A história da liberdade mostra que esse conceito tem uma base empírica nos movimentos sociais populares de luta pela terra de trabalho; portanto, tem sua raiz no movimento camponês. Do mesmo modo, todas as revoluções sociais no século XX (mexicana, russa, chinesa, vietnamita, boliviana, cubana, nicaraguense) foram, no total ou em grande parte, camponesas (Martins, 1989, p. 17; Ianni, 1985, p. 16).

Se a liberdade tem sua base em revoluções que ocorreram e efetuaram transformações, a emanci- pação, embora tenha sido tentada nas revoluções já ocorridas, é ainda um processo inconcluso; ela ainda é um horizonte não apenas contemplado, mas buscado. Para compreendê-la pesquisamos elementos nos escritos políticos de Marx (1979, 1985, 1986) e nos de Marx e Engels (1984), os quais partem da liberdade a caminho da emancipação. A liberdade é transpassada dialeticamente pela contradição que opõe, do lado positivo, a consciência e, do negativo, as necessidades básicas determinadas pelas condições materiais de existência que ampliam ou limitam o exercício da liberdade. Como autodeterminação, a liberdade supõe, vista por um ângulo, a eliminação dos obstáculos que impedem a emancipação, ou seja, a realização de todo o potencial presente na pessoa humana. Por outro ângulo, a organização social precisa abarcar a tridimensionalidade do humano, que é indivíduo, é natureza e é sociedade, de maneira articulada (Frigotto, 2002). Assim, em Marx e Engels a emancipação humana incorpora a liberdade, porém a supera ao incluir a dimensão natural e a social para além do indivíduo abstrato, no qual uma suposta razão, que seria superior, subordinaria as dimensões corporais e sociais.

A liberdade é o fim projetado pelo capitalismo; por isso, é princípio da ação, com destaque para a liberdade de mercado que a crise iniciada em setembro de 2008, com a falência de bancos privados e bolsas de valores, mostra não ter sustentação material concreta. A falência do livre mercado condena, assim, milhões de seres humanos ao estado de não-liberdade, por estarem excluídos das condições objetivas/subjetivas mínimas de existência. A emancipação, por sua vez, é um projeto do socialismo, mas as poucas e recentes experiências, que datam do século XX, evidenciam a necessidade de aperfeiçoar esse projeto, para incorporar, na unidade social, a diversidade dos processos de organização e manifestação humanas.

\section{Educação para o trabalho na pedagogia da alternância}

As ideias de liberdade e de emancipação, forjadas em acontecimentos históricos e retomadas numa bre- 
ve síntese, assumem novos formatos discursivos nas obras de autores que refletem sobre a relação entre a educação escolar e o trabalho, tendo por referência a produção industrial. Conserva, porém, a sua essência vinculada a processos sociais diferenciados e em conflito, exercendo, por sua vez, influência sobre as experiências pedagógicas que abordamos neste artigo. Com isso, retomamos o foco inicial da nossa análise: as experiências de trabalho-educação do movimento camponês.

As experiências pesquisadas, sejam as das CFRs e as das EFAs, sejam as da FUNDEP e as do ITERRA, alimentam suas práticas e concepções de liberdade ou de emancipação em autores cujas teorias datam, algumas, do século XIX adentrando pelo século XX, como a de Dewey; outras, das três primeiras décadas do século XX, como as de Pistrak, Makarenko e Krupskaya; outras indo um pouco além no tempo, como a de Piaget e Freire; e outra produzida por um autor ainda vivo, embora bastante idoso, que é Morin. Essa produção acontece nos Estados Unidos da América e na Europa, aí incluindo tanto o escolanovismo, o construtivismo e a complexidade como as teorias da escola socialista, formuladas por autores russos.

A exceção fica por conta da originalidade da teoria do educador brasileiro Paulo Freire (Ribeiro, 1999), que sistematiza experiências de educação popular efetuadas nos sertões nordestinos com populações rurais que viviam em extrema pobreza. Freire, o autor citado em todas as experiências, também registra o acompanhamento e os aprendizados decorrentes das experiências que tentavam articular estudo e produção agrícola nas áreas rurais libertadas no período revolucionário da Guiné-Bissau (Freire, 1977).

Essas teorias têm uma origem diversa no tempo e no espaço; mesmo assim, continuam sendo referência para as experiências pesquisadas. Por isso, vamos situar seus autores no contexto em que produziram suas obras em resposta aos desafios propostos pelo seu tempo. Assim, trazemos o escolanovismo de Dewey, nos Estados Unidos, o construtivismo de Piaget, na Suíça, e a complexidade de Edgar Morin, na França. Como contraponto, apresentamos as teo- rias produzidas em decorrência das experiências de trabalho-educação realizadas na Rússia, por Pistrak, Makarenko e Krupskaya. Finalizaremos com Paulo Freire, referido por todas as experiências pedagógicas brasileiras de trabalho-educação em regime de alternância. Nas concepções de trabalho-educação desses autores, buscaremos captar a compreensão dos princípios/fins de liberdade e de emancipação, nosso propósito neste artigo.

É na primeira metade do século XX - em que ocorrem as duas grandes guerras mundiais, a de 1914-1918 e a de 1939-1945 -, incluindo o período de transição entre elas e os anos que se seguem ao término da II Guerra, que se localiza a produção das teorias de Escola Nova e de escola socialista. Antes do término da I Guerra acontece a Revolução Russa de 1917; no período entre as duas guerras começa o processo revolucionário na China, concluído em 1949, portanto, após o término da II Guerra, quando acontece a Revolução Cubana, em 1959. Houve, ainda, processos revolucionários na Alemanha, Itália, Portugal e Espanha que acabaram por resultar em governos nazifascistas nos dois primeiros e em ditaduras nos últimos. ${ }^{1}$ Também houve movimentos de libertação nacional na Ásia e na África, em países que eram colônias da Inglaterra, Alemanha, França e Portugal. Processos produtivos industriais desenvolvem-se nesse período, tanto na Europa e nos Estados Unidos, com sua produção orientada pelo sistema capitalista, quanto na Rússia, pelo sistema comunista, exigindo uma reconceitualização da educação básica e profissional para adequar-se às necessidades decorrentes daqueles processos (Hobsbawm, 1995).

Esses acontecimentos impõem a necessidade de o capitalismo produzir reformas que contemplem o operariado com alguns benefícios resultantes da riqueza socialmente produzida. Com isso, o Estado liberal assume a forma de Estado do Bem-Estar e são adotados regimes social-democratas, com diferenças sensíveis em cada país em que vigorava o modo ca-

${ }^{1}$ Mussolini, na Itália; Hitler, na Alemanha; Franco, na Espanha; Salazar, em Portugal. 
pitalista de produção. A formulação e a aplicação de políticas públicas de bem-estar (entre elas a educação) por parte do Estado, associadas ao padrão tayloristafordista de produção, irão exigir um novo modelo de educação para o trabalhador. A educação contemplativa, tendo por finalidade o alcance de uma virtude abstrata, já não corresponde à formação demandada pelo processo fabril, em que a necessidade de operários disciplinados, produtivos, apaziguados, precisa estar associada à conquista de alguns benefícios sociais (Souza Santos, 1994; Harvey, 1998).

Nesse contexto, a Escola Nova é uma proposta para superar a escola tradicional, herdeira da Ilustração e estruturada sobre a memorização e a transmissão de conteúdos disciplinares. Com um ideário que ainda se mantém atual, a Escola Nova, como filha da Revolução Industrial sustentada pelo desenvolvimento científicotecnológico, ao contrário da escola tradicional, que é idealista, propõe a atividade como núcleo da educação escolar. Aprender a lidar com problemas concretos seria o método mais avançado para formar uma personalidade capaz de integrar-se à sociedade de forma criativa e democrática.

Os métodos adotados por ambas as escolas, Nova e tradicional, entretanto, estão compreendidos no projeto liberal de sociedade. Inicialmente, esse projeto precisa consolidar-se como Estado nacional, afirmando-se como classe perante o clero e a aristocracia. Para isso, defende uma formação para a cidadania isenta de privilégios. Mais adiante, consolidado o sistema capitalista, o processo de modernização irá demandar uma educação de caráter prático. No primeiro caso, a filosofia idealista alemã dá sustentação teórica ao Estado e à educação; no segundo, o idealismo cede lugar às ciências naturais transformadas em forças produtivas; o positivismo, aplicado às ciências humanas e sociais, justifica o modelo de desenvolvimento capitalista e, consequentemente, de escola que ele demanda.

O conceito de homem que sustenta os dois métodos mantém-se como uma abstração porque omite ou considera naturais as contradições peculiares a um modo de produção gerador de classes sociais antagônicas em relação. Esse conceito de homem incorpora a polis (grega) ou a civitas (latina) como o lugar da civilização, o que exclui aqueles que sustentam suas necessidades através do trabalho, permitindo-nos antever os limites do escolanovismo para a formação de agricultores cidadãos. Isso porque o conceito e a prática da cidadania excluem os agricultores, sua cultura e seu trabalho (Ribeiro, 2002).

Os ideais escolanovistas são sistematizados pelo educador, psicólogo e filósofo norte-americano John Dewey já no final do século XIX. Ele pensa a educação na dimensão pragmática e instrumental, voltada à integração numa sociedade democrática, sem questionar a existência das classes sociais. Dewey é contrário à separação entre vida e instrução; por isso argumenta em favor da educação baseada na experiência; pensa que, em vez de o professor trazer exemplos de situações ideais já com respostas prontas a serem memorizadas, é preciso propor problemas que preparem os alunos para formular alternativas de soluções.

O escolanovismo de Dewey orienta-se para a conciliação entre as posições expressas pelo anarquismo e pelo autoritarismo pedagógico, referindo-se, no caso, tanto à educação tradicional quanto à socialista, uma vez que o regime comunista russo é visto pelo autor como totalitário. Liberdade, iniciativa e interesse produtivo da criança fundamentam o ensino pela ação, voltado ao progresso da sociedade. Para isso, a escola deve apresentar-se como uma comunidade embrionária ou em miniatura, em que o aluno possa exercitar o pensamento e a ação em situações concretas de aprendizagem. Educar é praticar a democracia desde a escola, onde a criança dispõe de materiais, orientações e ambientes adequados para avaliar-se constantemente e reorganizar suas experiências. Educação é, portanto, ação.

Nesta breve síntese do pensamento de Dewey evidenciamos sua concepção de liberdade associada à democracia liberal, em que o acesso à educação daria condições aos indivíduos de conquistar a cidadania e a liberdade de participação na sociedade. Entre outras obras, o pensamento deste autor é expresso em Liberalismo, liberdade e cultura (1970), no capítulo II, em que trata da relação entre a liberdade e a cul- 
tura. Publicado em 1935, observa-se a preocupação do autor em trazer à discussão o sentido da liberdade no período de interregno entre as duas guerras mundiais, considerando que já havia ocorrido, em 1917, a Revolução Russa e estava se iniciando, em 1934, o processo revolucionário na China.

Dewey associa a sua compreensão da liberdade à “ideologia” expressa na Declaração da Independência dos Estados Unidos da América. Para o autor, essa expressão clássica da liberdade americana incorpora a ideia de que ela é tanto uma conquista quanto uma meta histórica, uma vez que “autogoverno é o direito inerente dos homens livres e que isso, uma vez obtido, é o que os homens prezam acima de tudo o mais” (Dewey, 1970, p. 98). A esse seu entendimento da liberdade contrapõe a situação de países em que, na sua percepção, os homens e as instituições estão deixando de ser livres - em alguns casos, até com certo entusiasmo. $\mathrm{O}$ autor sustenta sua concepção de liberdade relacionando-a com a teoria que interpreta o homem como um ser de natureza, sujeito às leis e aos direitos naturais, próprios de uma sociedade também natural. A essa concepção do homem e da sociedade, Dewey relaciona as leis psicológicas e as teorias políticas que orientaram as lutas para garantir a independência norte-americana. Assim, pensa que, se essas concepções sobre a natureza humana e sobre os fins morais orientadores das ações forem deixadas de lado e, em consequência, também o direito à liberdade historicamente conquistada pelos Estados Unidos, poderia existir "alguma coisa que lhes possa tomar o lugar, alguma que dê o suporte e o apoio que elas antes deram?" (idem, ibidem, p. 99).

O movimento da Escola Nova situa-se em um processo mais amplo de mudanças que ocorriam na sociedade que se urbanizava, exigindo, além da ampliação do sistema escolar, um ensino que preparasse os alunos para enfrentar mudanças. Cabia à escola, nesse contexto, a função de corrigir as desigualdades sociais pela oferta de uma formação que possibilitasse ao indivíduo obter um emprego e ascender socialmente. Nessa perspectiva é que o escolanovismo pode ser entendido como uma pedagogia liberal.
Dewey posiciona-se contrário à importância conferida à filosofia nos Estados Unidos, "definindo a educação como lugar e prática da reflexão, apoiada pela psicologia, para a criação de um método 'consciente’ de ensino” (Luedemann, 2002, p. 14), o que pode explicar a relação que se estabelece entre a Escola Nova e a psicologia genética de Piaget. Embora sendo produto da realidade europeia, a teoria de Piaget, também conhecida como construtivismo, aproxima-se do escolanovismo de Dewey, o que explica a indicação de ambos como autores que sustentam a pedagogia da alternância nas CFRs e EFAs.

O aprender é um "tornar-se”, para Piaget. Ele ressalta o dinamismo do conhecimento através da análise, contrapondo-se a uma concepção afirmada em uma essência imutável, cujo ser idêntico a si mesmo só pode ser explicado numa síntese. Ressaltando a ação espontânea do sujeito, o construtivismo opõe-se à teoria da representação da realidade, base da escola tradicional, no que concorda com Dewey. Não pretende, com isso, apresentar a solução definitiva para as questões da escola que não se resumem aos métodos de ensino. Não se pode deixar de enfatizar a proximidade de Piaget com a Escola Nova, relacionando a aprendizagem intelectual ao desenvolvimento da inteligência na ação de construir o conhecimento.

Em suas obras, Piaget contesta o ensino memorizativo (Piaget, 1976b) e o uso do condicionamento para reforçar associações motoras (Piaget, 1976a). Mas questiona principalmente o ensino de filosofia ou de metafísica com métodos em que se destacam a erudição e o raciocínio subjetivo através da introspecção (Piaget, 1975). Ele afirma que os educadores importantes que deixaram seu nome na história não são pedagogos e que, no período de 1935 a 1965, “nenhum grande pedagogo apareceu na lista dos homens eminentes que marcaram a história da pedagogia” (Piaget, 1976b, p. 17). Apesar dessa visão negativa dos pedagogos, não responsabiliza os professores, os quais seriam desestimulados pela desvalorização social e estariam presos a programas determinados pelo Estado. Impossível saber se, ao fazer esta afirmação, Piaget tinha conhecimento da obra do pedagogo russo 
Makarenko, que escreveu o Poema pedagógico (s.d.) num período de dez anos (1925-1935), ${ }^{2}$ ou se, de fato, não considerava seu trabalho pedagógico, até pelas críticas feitas ao pedagogo russo, acusado de silenciar diante do despotismo de Stálin.

O construtivismo é uma teoria da ação; contrapõese, dessa forma, ao ensino baseado na transmissão de conhecimentos, cujo instrumento principal é a linguagem. Com isso, o ensino está centrado nas ações dos alunos, organizadas como esquemas de assimilação que permitam classificar, relacionar etc. Piaget contesta modelos fechados de aprendizagem, buscando reconstituir as situações nas quais se produziram os conhecimentos. Desenvolve um trabalho de regulação, com esquemas de ação direcionados para objetivos, de modo que reconstitua processos de construção dos conhecimentos; por isso sua identificação como construtivismo. Não se atém à forma, uma vez que esta tende a desvincular-se do conteúdo ou do contexto em que foi gerado o conhecimento que se pretende trabalhar.

A ênfase sobre o aluno como sujeito do ato de conhecer pode conferir menor importância aos demais elementos presentes numa relação pedagógica, que são, nesse caso, o professor, os materiais de aprendizagem e as condições histórico-sociais em que os alunos, os professores e essas condições estão inseridos. Mesmo reconhecendo a importância da interação entre o sujeito e o meio, a época e o modo como foram realizadas as experiências pelo próprio Piaget em seu país, a Suíça, podem limitar a compreensão dos processos cognitivos, uma vez que restringem as condições concretas de realização dos registros e das observações ao processo pedagógico.

A maioria das teorias que sustentam as organizações curriculares nos diferentes níveis de ensino como suas práticas são orientadas por teorias psicológicas, colocando o indivíduo como centro da ação educativa. O construtivismo piagetiano é, talvez, uma das mais influentes, o que explica a sua indica-

\footnotetext{
${ }^{2}$ Ver “Apresentação” de S. Telingater em Poema pedagógico, v. 1 (Makarenko, s.d., p. 7).
}

ção pelos pesquisadores ligados às CFRs e às EFAs. No entanto, são feitas críticas a esse construtivismo porque a sua aparente indiferença política lhe permite combinar-se com reformas de cunho neoliberal, contribuindo para fortalecer a ideologia do livre mercado (Silva, 1998), apesar de proclamar-se democrático, crítico e emancipatório. Na mesma direção, Duarte (2001, p. 2) identifica a "concepção psicológica e epistemológica interacionista-construtivista de Piaget" como associada ao lema "aprender a aprender”, interpretado pelo autor "como uma expressão inequívoca das proposições educacionais afinadas com o projeto neoliberal”.

O terceiro nome que mais aparece nas indicações dos educadores envolvidos com as CFRs e EFAs é Edgar Morin. Suas obras inscrevem-se no debate sobre as relações entre as ciências, em que a configuração disciplinar que estas adotam resulta em enorme fragmentação, principalmente considerando o avanço do conhecimento em determinadas áreas. Isso, segundo Morin, dificulta a compreensão dos desafios colocados às sociedades contemporâneas. Diante dos problemas cada vez mais complexos que as sociedades enfrentam, o autor propõe o reencontro das ciências com o humanismo, porque somente estudos de caráter inter-poli-transdisciplinar podem contribuir para dar respostas satisfatórias àqueles problemas (Morin, 2003). A metáfora da complexidade, adotada pelo autor, inspira-se no tecido, porque este se constitui de elementos heterogêneos indissociáveis, próprios da totalidade que compreende uma multiplicidade de elementos.

Aprofundando a análise, o autor explicita a complexidade do que é tecido pelos acontecimentos, constituídos de ações, reações, determinações e acasos que integram o mundo fenomênico, o qual se nos apresenta como confusão, desordem e, por isso mesmo, incerteza. Assim, as ciências naturais justificam a necessidade de colocar em ordem os fenômenos para que se possa obter o conhecimento, retirando dele a desordem, a dúvida, a incerteza. Permanecem apenas os elementos da ordem, da clareza, da certeza, permitindo distinguir e hierarquizar esses elementos. 
“Mas tais operações necessárias à inteligibilidade correm o risco de torná-la cega se eliminarmos os outros caracteres do complexus; e efetivamente, como o indiquei, elas tornam-nos cegos” (Morin, 1990, p. 19). A complexidade proposta por Edgar Morin, portanto, é uma abordagem transdisciplinar dos fenômenos que busca a superação do reducionismo peculiar à pesquisa científica, abrindo espaço à aceitação do caos como possibilidade de criação de novos ordenamentos e novas invenções.

A abordagem de Morin situa-se no contexto das críticas às ciências experimentais orientadas pelo paradigma baconiano. Este, além de deixar de fora o humano transformado em objeto, não considera a existência de outras leituras sobre o mundo fenomênico. Essa é uma contribuição importante no processo de ampliação dos espaços de produção e divulgação do conhecimento científico que, entretanto, não altera a base da produção dos bens materiais e imateriais, em que a riqueza e o conhecimento socialmente produzidos são apropriados privadamente.

Numa visada superficial, a complexidade de Morin parece ampliar o olhar para democratizar os espaços de participação e considerar o caos e a incerteza como desafios à criatividade humana. Adentrando a sua essência, do mesmo modo que o construtivismo piagetiano, a sua aparente indiferença política mostra a fragilidade de seus postulados. Em primeiro lugar, porque não se coloca a questão das relações de produção/ apropriação da ciência, sendo esta também uma força produtiva. Em segundo, porque o caos e a incerteza, compreendidos na natureza mesma da complexidade, de algum modo podem justificar a necessidade de conviver, de forma criativa, com a realidade do desemprego. Cabe ao indivíduo enfrentar o caos e a incerteza próprios da complexidade, respondendo ao desafio de buscar e não encontrar emprego, sem, no entanto, modificar o sistema que origina a produção do desemprego e a miséria social de milhões de pessoas no mundo. Ou mesmo conformar-se em conviver com esta incerteza, pois, nessa linha de pensamento, conforme denuncia Freire (2001, p. 63), propaga-se o discurso de que "Não há o que fazer, o desemprego é uma fatalidade do fim do século".

Trazendo essa discussão para os sujeitos do movimento camponês, torna-se mais fácil compreender o deslocamento da formação do técnico agrícola para a do sujeito “empreendedor”. Se a teoria da complexidade reforça a liberdade do indivíduo de escolher e tomar decisões, aponta para uma liberdade abstrata, situada acima do mundo fenomênico ou das condições materiais de existência em que vive esse indivíduo, contraditando com o objetivo pretendido pelo autor.

Na educação feita nas CFRs, nas EFAs, através da pedagogia da alternância de trabalho agrícola e educação escolar, principalmente nos programas de formação de jovens empresários rurais, é muito forte a influência do construtivismo piagetiano aliado às concepções da Escola Nova, de Dewey. Um exemplo é o do Programa Nacional de Inclusão de Jovens (Pró-Jovem), que associa a educação profissional básica e a preparação para o trabalho e no qual a agricultura familiar é a atividade predominante. Embasada no construtivismo, alterna um período de estudos durante uma semana na escola com outro de trabalho, durante três semanas, na propriedade familiar, colocando em prática os conteúdos que recebe na escola (Instituto Souza Cruz, 2004, p. 70-77, reportagem de Jorge Serrão).

Na Escola Nova de Dewey, no construtivismo de Piaget e na complexidade de Morin, a concepção de liberdade - que irá subsidiar a proposta pedagógica das CFRs e das EFAs - está relacionada ao exercício de uma cidadania ativa. Também pode ser compreendida como autonomia com o significado de emancipação, que aparece algumas vezes associada ao autogoverno e à capacidade do indivíduo de autossustentar-se. Portanto, liberdade e emancipação, nessas teorias, referem-se a princípios que orientam o comportamento dos indivíduos na sociedade liberal, sendo a educação o instrumento essencial da liberdade e de conquista da autonomia. A escola centrada no sujeito que age, que aprende a resolver problemas, que enfrenta os desafios da incerteza coloca, para todos, as condições de competir no mercado por melhores condições de vida e de trabalho e de participar no desenvolvimento local e regional (Ceffas, 2005; Begnami, 2004; Du- 
ffaure, 1997). Enquanto possibilidade de superação das relações entre as classes sociais, incorporando a liberdade articulada à igualdade de condições de seu exercício, a emancipação humana não é projetada nessas experiências de trabalho-educação efetuadas pelas CFRs e pelas EFAs.

\section{Trabalho-educação na pedagogia do tempo-comunidade e tempo-escola}

Passaremos à análise das concepções que embasam uma proposta de escola socialista, de Pistrak, Makarenko e Krupskaya, que, por sua vez, dão suporte teórico e ideológico às experiências de trabalhoeducação realizadas pela FUNDEP e pelo ITERRA (MST, 2005). Esses educadores, em condições bastante difíceis para um país pobre e em processo de consolidação de uma revolução social, projetaram elementos básicos da pedagogia socialista nos quais se inspiram os movimentos sociais populares organizados na Via Campesina, que desenvolvem experiências de tempos/espaços alternados de trabalho-educação na FUNDEP e no ITERRA.

Logo após a Revolução Russa, lideranças na área da educação retomaram criticamente a relação entre instrução e trabalho produtivo, um tema colocado pela pedagogia moderna. Inspirados nas obras de Marx, Engels e Lênin, educadores formularam uma concepção coerente com essa ideologia e efetuaram experiências para aplicá-la. No pensamento socialista, a relação entre educação e trabalho vai além da simples agregação da instrução tradicional com a educação profissional para um trabalho determinado; trabalho e educação sustentam a formação do homem omnilateral. Do mesmo modo que a Escola Nova, a educação socialista opõe-se à educação tradicional. Manacorda (1989, p. 314-315) faz referência às contribuições de Krupskaya e Lênin, baseadas em Marx, para a instituição de "uma escola única do trabalho" Também cita Makarenko, autor de uma pedagogia original, não-espontânea, contrapondo-se à literatura pedagógica de sua época.

Pistrak desloca as preocupações, antes dire- cionadas aos métodos de ensino, para os princípios pedagógicos, aproximando-se das ideias políticas e pedagógicas de Krupskaya, companheira de Lênin. A obra Fundamentos da Escola do Trabalho (Pistrak, 1981), cujo prefácio do autor data de 1924, registra o trabalho pedagógico realizado na Escola Lepechinski. A educação russa, nos anos de 1920, é influenciada pelas experiências de Pistrak, que apontava para a necessidade de um novo homem preparado para atuar na nova organização social russa. Diferentemente do que se fizera antes, a educação socialista deveria formar pessoas conscientes, envolvidas na construção da nova sociedade. “A pedagogia marxista é e deve ser antes de tudo uma teoria da pedagogia social, ligada ao desenvolvimento dos fenômenos sociais, atualmente dados e interpretados do ponto de vista marxista” afirmava Pistrak (1981, p. 28).

Na Europa e nos Estados Unidos eram aplicados os fundamentos da Escola Nova, associando teoria e prática, estimulando a participação dos alunos, difundindo a ideia do aprendizado constante e da responsabilidade de cada um quanto aos direitos de cidadania. Porém, na Rússia, se a Revolução pretendia instituir novas relações sociais, era necessário um projeto pedagógico voltado à formação do homem socialista, ou seja, não bastava transmitir conteúdos revolucionários adotando métodos tradicionais, pensava Pistrak. Na sua obra destaca: a) a necessidade de conhecer a realidade para intervir sobre ela, do que decorre a importância da pesquisa já na escola; b) a auto-organização dos educandos, vivenciando as funções de direção e de subordinação; c) o método dos complexos, em que se destaca a interdependência que contribui para uma atuação concreta e adequada sobre a realidade no sentido de transformá-la. Pistrak critica os professores russos ainda influenciados pelas ideias da Escola Nova, produzidas nos Estados Unidos e na Europa, sem fazer uma crítica cuidadosa do que se pretendia como uma pedagogia nova, porque, "sem teoria pedagógica revolucionária, não poderá haver prática pedagógica revolucionária”. Do mesmo modo, pensa que, "sem uma teoria da pedagogia social, nossa prática levará a uma acrobacia sem finalidade social e utilizada para resolver os problemas pedagógicos na base das 
inspirações do momento” (Pistrak, 1981, p. 29).

Outro educador citado nos documentos que orientam a formação da FUNDEP e do ITERRA (Caldart, 1995, 1997; FUNDEP, 1995, 1996; ITERRA, 2004) é Makarenko, autor do Poema pedagógico (s.d., v. I, II, III). Sua teoria pedagógica funda-se na autoridade social, privilegiando as questões coletivas sobre as individuais. Justificam-se, assim, os castigos para obter uma disciplina que venha a beneficiar o grupo. Sua obra inspira-se nas experiências pedagógicas por ele coordenadas na Colônia Gorki e na Comuna Dzerjinki, em que realizou um trabalho de formação com órfãos da guerra civil. Para Makarenko, a escola é o núcleo básico da sociedade comunista, onde se forja o homem solidário; por isso precisa ser uma comunidade de interesses comuns, e não um agrupamento de indivíduos isolados. A liberdade individual encontra seu limite no bem maior da comunidade; por isso não se admitem hesitações quando se trata de usar a "autoridade da ajuda" incutindo a norma naqueles que colocam seus interesses individuais acima dos interesses coletivos.

Na pesquisa sobre a obra e a vida de Makarenko, Luedemann (2002) procura desfazer algumas interpretações sobre este pedagogo, que, pela ênfase no coletivo sobre o individual, tem sido criticado como autoritário. Makarenko não pode ser identificado "seja como restaurador da escola burguesa e autoritária, seja como criador de uma escola contra o desenvolvimento livre do indivíduo e a forma de massificação a favor da educação stalinista, seja como criador de uma nova escola socialista”, pensa Luedemann (2002, p. 21). Destacam-se, na obra de Makarenko, as seguintes ideias: a) formação para a organização das coletividades; b) pedagogia da revolução, de modo que essa não degenere em acomodação; c) relação entre trabalho produtivo, instrução e autogestão; d) formação de um trabalhador culto, que saiba comandar e obedecer (Capriles, 1989).

O terceiro nome indicado nas experiências da FUNDEP e do ITERRA é o de Nadezhda Konstantinovna Krupskaya; há poucas informações e publicações a respeito dela e do trabalho político-pedagógico que desenvolveu. Krupskaya pensava que, nos propósitos da Revolução, seria preciso ampliar as possibilidades para os trabalhadores frequentarem a escola. Ao lado de Lunatcharski, comissário para a Instrução Pública, essa educadora "criou um sistema único de ensino, garantindo o acesso universal à educação pública e gratuita” (Luedemann, 2002, p. 16). Também desenvolveu trabalhos de instrução política das massas, a partir de 1920; antes isso era impossível porque a revolução e a participação da Rússia na I Guerra impunham a solução de problemas mais urgentes.

Do processo de agitação que mobilizava as camadas populares para a luta armada contra o inimigo, era preciso desenvolver uma educação política sistemática, pensava Krupskaya. Com isso seriam oportunizadas condições, aos operários e camponeses, para aprofundar os êxitos da revolução e formular respostas às tarefas para a consolidação do socialismo. Krupskaya também se preocupava com a formação política do campesinato; pensava que o socialismo não poderia consolidar-se sem provocar mudanças que retirassem os camponeses pobres de seu isolamento, criando condições de cooperação entre eles e a classe operária (Coletivo de Autores Soviéticos, 1987).

Os autores russos que orientam a formação em TC e TE na FUNDEP e no ITERRA colocam como horizonte da educação a construção do socialismo, por isso suas preocupações estão direcionadas para a emancipação humana. Com isso, deslocam-se da liberdade do indivíduo cidadão e da autonomia conquistada através de um emprego assalariado - objetivos apontados pelos autores do escolanovismo, do construtivismo e da complexidade - para a emancipação que garanta a liberdade e a autonomia para todos. Entretanto, esses esforços para ampliar direitos sociais, como a educação para além do indivíduo, por exemplo, não estão isentos de contradições.

Voltando às origens da pedagogia socialista e aos autores que a propuseram e colocaram em prática, é preciso, ao analisá-las, levar em conta a pobreza do povo russo, a revolução concomitante à participação na I Guerra Mundial e o retorno dos soldados para reconstruir a vida, o trabalho e o país, ou seja, o contexto 
em que foram produzidas as experiências pedagógicas dos educadores russos. Poucas de suas obras chegaram ao Brasil, a maioria traduzida do russo para o espanhol. O processo revolucionário, o retorno depois da guerra e o enfrentamento de questões urgentes, como a fome, desenhavam um contexto em que quase tudo estava por ser feito e inventado. A Revolução Russa, geradora de uma esperança coletiva que se estendeu de 1918 a 1929, foi "enterrada pela hegemonia da burocracia sob Stálin”, que veio substituir Lênin no poder soviético (Tragtemberg, 1981, p. 8).

Além do boicote dos países capitalistas, um dos maiores desafios para a consolidação do socialismo era a relação entre o operariado e o campesinato. É possível que a educação como formação humana na perspectiva da emancipação social tenha sido percebida como alternativa. Ou, quem sabe, as organizações sociais populares russas em determinadas conjunturas, como o boicote, principalmente dos Estados Unidos e da Europa, tenham concentrado suas preocupações com a formação humana efetuada através de uma escola que articulasse o trabalho produtivo à educação escolar. De modo semelhante, isso pode estar ocorrendo em relação à Via Campesina, no Brasil, diante da relação do Estado com o MST e da pressão do movimento reacionário ruralista, presente no Congresso Nacional como União Democrática Ruralista (UDR), conforme fica claro na obra organizada por Melo (2006).

É preciso reconhecer, no entanto, que a formação humanista efetuada pela FUNDEP e pelo ITERRA associa a liberdade da pessoa à emancipação social, considerando a autonomia do/no trabalho cooperado articulada à autonomia de os movimentos sociais populares definirem suas estratégias de organização e luta na unidade do movimento camponês. Nesse sentido, podemos afirmar que suas práticas/concepções de trabalho-educação estão dirigidas para a construção do projeto popular de sociedade e educação - ou para a emancipação humana, cuja compreensão transcende o indivíduo. Mesmo levando em conta as contradições peculiares ao modo capitalista de produção que impregnam também as experiências pedagógicas do movimento camponês, e até por isso, é preciso considerar que a emancipação humana é uma construção histórica. Ela é princípio/fim educativo que pressupõe a liberdade de escolha, a autonomia do trabalho, mas vai além ao propor a igualdade de condições para que liberdade e autonomia sejam acessíveis a todos.

\section{Paulo Freire: a unidade na diversidade}

A relação trabalho-educação como base de uma formação humana omnilateral começa a ser esboçada por Marx (1982), em seguida por Lênin (1977), ampliada por Gramsci (2001) e colocada em prática em experiências realizadas na Rússia, após a revolução, por Pistrak, Makarenko e Krupskaya, estendendo-se pelos anos de 1920 e meados dos anos de 1930. Nessas fontes engendram-se os princípios/fins de liberdade da pessoa humana relacionada dialeticamente à emancipação social enquanto alicerces que sustentam as experiências de trabalho-educação-cooperação no tempo-escola e no tempo-comunidade, realizadas pela FUNDEP e pelo ITERRA.

A Escola Nova, ou escola ativa, e o construtivismo piagetiano são concepções que embasam a educação para o trabalho oferecida nas escolas do ensino básico e profissional nos países em que vigorava o capitalismo. Por sua vez, a complexidade é pensada por Morin em um momento no qual ocorrem debates, na Europa, nos anos de 1990, sobre uma espécie de caos em que a ciência, por mais que esteja desenvolvida, não consegue abarcar. Do mesmo modo, a incerteza atinge a estabilidade dos postos de trabalho gerados pelo capitalismo, sinalizando para a incerteza, ao mesmo tempo, como desafio e possibilidade de serem criadas alternativas, situando-se a teoria da complexidade nesse contexto. Essas são as fontes que alimentam os princípios/fins de liberdade do indivíduo associada à autonomia do/ no trabalho, presentes nas experiências de pedagogia da alternância realizadas pelas CFRs e pelas EFAs.

Um nome aparece em todas as experiências efetuadas pelas CFRs e EFAs, pela FUNDEP e pelo ITERRA, em que se alternam o trabalho agrícola e a educação escolar. Trata-se do educador pernambucano 
Paulo Freire. Ainda que suas ideias sejam aplicadas por enfoques diferentes, umas enfatizando o método de alfabetização e outras a possibilidade de romper a relação entre opressor/oprimido, seu pensamento é a síntese das propostas pedagógicas desenvolvidas pelo movimento camponês. Essa é a razão pela qual deixamos o diálogo com este autor para o final, buscando apreender em sua práxis - pedagógica e política - como se exprimem os princípios de liberdade e emancipação. Para isso, localizamos seu pensamento no interior das tendências filosóficas e correntes pedagógicas que influenciam a educação brasileira, retomando estudos feitos em Ribeiro (1999).

Não vamos trazer dados biográficos de Paulo Freire, nem rebater críticas a ele dirigidas, principalmente por Vanilda Paiva (1984), que se referem a um determinado período de sua atuação e produção, porque vários autores, entre os quais Rossi (1982) e Gadotti (1993) já o fizeram. Esses autores registram nos primeiros trabalhos de educação popular iniciados no estado de Pernambuco por Freire, as influências de sua formação católica, do existencialismo cristão e do personalismo de Mounier. Aqui é possível estabelecer um vínculo entre o pensamento freireano e algumas das experiências de pedagogia da alternância que indicam Mounier como um dos autores que sustentam suas práticas. Mais tarde, quando Freire começou a ser perseguido pela ditadura militar que se instalou no Brasil em 1964 e viajou para o Chile, aproximou-se do marxismo sem, no entanto, abdicar de outras vertentes filosóficas e de suas crenças religiosas. Foi quando escreveu, em 1970, a Pedagogia do oprimido (Freire, 1981).

Reconhecido por seu método de alfabetização de adultos, Paulo Freire desenvolve um pensamento que expressa uma preocupação epistemológica que transpassa a associação entre a palavra e o signo para projetar-se enquanto leitura, compreensão e inserção do analfabeto no mundo, como sujeito de história (Andreola, 1993). Constituído e vivenciado como práxis, é nessa perspectiva que o seu projeto pedagógico pode traduzir-se numa pedagogia emancipante, em se fazendo. Isso por sua capacidade de levantar questões e apontar pistas aos educadores em um meio no qual grassa o relativismo, a competição e a desesperança provocados tanto pela política subordinada à "liberdade de mercado” quanto pelas teorias pós-modernas e pós-estruturalistas que contestam as utopias sociais e educacionais.

A originalidade do pensamento de Paulo Freire já havia sido apontada por Gadotti, um dos estudiosos de sua obra. Assim, o que nos propomos a destacar é a natureza epistemológico-política da pedagogia freireana, vista como uma tendência original no pensamento educacional brasileiro, mais precisamente a dimensão emancipante da educação popular praticada e pensada por Freire. Assim, caracterizamos a pedagogia freireana como emancipante. Apelando para o gerúndio - emancipando - ela se traduz pela ideia de processo, de busca, de movimento, de possibilidade de superação, de gerar a nova pedagogia por dentro da velha educação formal. Isso porque a expressão emancipatória incorpora uma compreensão do que já foi feito, do que já foi atingido e conquistado, afastando-se do sentido da emancipação, apontada como um horizonte das lutas dos movimentos sociais populares por Marx e Engels. Entre a liberdade e a emancipação, colocadas como princípios e ao mesmo tempo como fins, mediando-as, situa-se a pedagogia freireana como emancipante.

O caráter emancipante da pedagogia freireana destaca-se principalmente em três pontos: a) na perspectiva epistemológica, que rompe com a tradição filosófica e pedagógica autoritária importada, encaminhando-se à formulação de um pensamento educacional brasileiro autônomo; b) na educação popular como projeto de classe, que se amplia para abarcar, além dos pobres, todos os seres humanos que, de algum modo, vivenciam situações de opressão e discriminação - as quais ultrapassam as relações sociais de produção -, como as mulheres, os negros, os índios, os migrantes, os meninos de rua; c) na ação política em que o exercício da liberdade "nos leva à necessidade de optar e esta à impossibilidade de ser neutros" (Freire, 2003, p. 68).

Em suas obras, das quais citamos algumas, Paulo Freire $(1978,1979,1981)$ focaliza os adultos 
analfabetos como sujeitos de educação e produção de conhecimento. Em sua abordagem, argumenta que o processo formal de aprendizagem realizado na escola não contempla esses sujeitos. A possibilidade de abertura do diálogo com o educando, de um lado, e a inexistência do diálogo, ou o não-diálogo, de outro, são apontados como referências para diferenciar uma educação libertadora de uma educação opressora. Nas primeiras experiências de educação popular, caracterizadas pela negação ao modelo criticado de escola formal, afirma, com ênfase, que "ninguém educa ninguém” (Freire, 1981, p. 79); o conteúdo é construído em conjunto pelo educador e pelo educando, que investigam, no universo temático do povo, os temas geradores (idem, ibidem, p. 102). Essas afirmações de Paulo Freire, de certo modo, foram interpretadas como negação da escola, suscitando críticas de Vanilda Paiva (1984).

Na abordagem dialética da pedagogia libertadora proposta por Freire (1981), o oprimido, atravessado pela contradição, hospeda dentro de si o opressor. Por isso é importante essa descoberta, que assume a dimensão de um parto da pedagogia libertadora quando rompe com a dupla face do ser e do parecer. É na ênfase dada por Freire a essa descoberta e à superação que se compreende o sentido da luta dos oprimidos para que, ao descobrir-se e ao libertar-se, não venham a ocupar o lugar do opressor. Portanto, o sentido da liberdade, para Freire, transcende os limites do indivíduo, da sua vida particular e do seu trabalho para abarcar a humanidade, ou melhor, aqueles que estão mergulhados em situações de desumanização, ou seja, excluídos das condições sociais de humanização, que seriam próprias dos seres humanos, de todos eles.

Mas por que Paulo Freire é a referência para as experiências em que se alternam tempos/espaços de escola e de trabalho, do movimento camponês, apesar das divergências entre elas, de concepções de liberdade e emancipação e dos autores que as sustentam? Uma pesquisa na obra desse educador mostra uma relação profunda entre suas concepções político-pedagógicas e suas experiências com a educação de camponeses, que tem sido caracterizada como educação popular
(Paludo, 2001; Souza, 2007). Essa pode ser uma resposta. Aprofundando-a, encontramos no livro Cartas à Guiné-Bissau (1977) registros de acompanhamento das experiências pedagógicas associadas a um processo revolucionário nas áreas rurais, que se haviam libertado da dominação portuguesa. Nessa obra fica claro que trabalho-educação, em Paulo Freire, tem por referência o trabalho do camponês articulado com a aprendizagem escolar. O objetivo de integrar as atividades escolares regulares ao trabalho produtivo seria “combinar trabalho e estudo de tal maneira que aquele fosse, tanto quanto possível, constituindo-se como fonte do último, em unidade com ele” (Freire, 1977, p. 73-74). O trabalho produtivo, de caráter coletivo, vem dando a educandos e educadores uma visão distinta de sua formação em comum, vem inserindo a escola nas comunidades, como algo que delas emerge.

Paulo Freire - como autor-síntese dos princípios/ fins de liberdade e emancipação que sustentam as experiências de trabalho agrícola e educação escolar do movimento camponês - explica-se pela coerência de sua vida com sua obra, em que, na luta pela conquista da emancipação humana, está implícita a liberdade de cada um dialeticamente articulada à igualdade de direitos de todos.

\section{Liberdade-emancipação e trabalho-educação no movimento camponês: contradições}

Ao longo da história, das lutas por liberdade, pela autonomia do trabalho e pela terra para aqueles que nela vivem e trabalham, o movimento camponês constrói-se como um sujeito político coletivo, integrante do sujeito histórico revolucionário, o proletariado despojado de bens e direitos. As teorias liberais e o marxismo evolucionista que, em suas análises, têm destinado o movimento camponês ao desaparecimento, surpreendem-se, a cada dia e em cada país, com o vigor de suas lutas e de sua presença. Camponeses e operários como sujeitos constituintes do sujeito histórico da transformação social deixam transparecer em suas ações um projeto de superação da relação de antagonismo entre cidade e campo, base 
do modo de produção capitalista. Embora esse seja um projeto vivo, em movimento, por isso atravessado pelas contradições próprias das relações entre capital e trabalho, nele se redefinem as concepções de liberdade, autonomia e emancipação. Enquanto educador e constituidor/constituinte da classe revolucionária, o movimento camponês, associado ao movimento operário, constrói-se como sujeito histórico que projeta a emancipação humana.

O movimento camponês, no Brasil, tem obtido importantes conquistas, principalmente na educação do campo, uma proposta de afirmação dos sujeitos políticos coletivos que vivem do trabalho com/da terra e que, historicamente, têm sido anulados na educação rural que lhes tem sido oferecida. Dessas conquistas ressaltamos as Diretrizes Operacionais para a Educação Básica das Escolas do Campo e o Programa Nacional de Educação da Reforma Agrária (PRONERA), este vinculado ao Instituto Nacional de Colonização e Reforma Agrária (INCRA) e não ao Ministério da Educação (MEC). Todavia, se de um lado, as Diretrizes e o PRONERA, conquistados em mobilizações, marchas e conferências de educação do campo, estão registrados em leis, de outro, muitos obstáculos se colocam para que sejam postos em prática. Entre esses obstáculos se incluem: as dificuldades para a liberação dos recursos mesmo após a aprovação dos projetos de formação; a recusa em aceitar a prestação de contas do uso de recursos em atividades pedagógicas, feitas pelo ITERRA, principalmente as desenvolvidas pelo MST; o encerramento do convênio com a Universidade do Estado do Rio Grande do Sul (UERGS) para a realização de cursos de graduação efetuados na FUNDEP e no ITERRA. Contrapondo-se à educação rural que não considera os agricultores e agricultoras como produtores sociais de vida e conhecimento, o movimento camponês recria, na pedagogia em que se alternam trabalho agrícola e educação escolar, a formação humana integral referida ao movimento operário (Ribeiro, 2008, 2009).

A exposição feita até aqui permite afirmar que as experiências, nas quais se alternam trabalho e educação nas CFRs, nas EFAs, na FUNDEP e no ITERRA são orientadas por concepções e princípios de liberdade e emancipação cujos significados divergem. As CFRs e as EFAs orientam a formação em pedagogia da alternância nas concepções da Escola Nova, formuladas por Dewey, no construtivismo de Piaget e na teoria da complexidade de Morin. Nessas concepções, o aluno é o centro do processo de ensinar/aprender; a ênfase recai sobre a construção do conhecimento, a resolução de problemas e a criatividade para enfrentar os desafios dos atuais tempos de incerteza. Atentando ao objetivo colocado de início, temos que nessas experiências a liberdade está relacionada ao exercício de uma cidadania ativa para intervir no desenvolvimento local e regional, orientando-se pelo modelo de política representativa para atuar dentro do Estado liberal. Precisamos, entretanto, levar em conta que as contradições também estão presentes nessas organizações pedagógicas e sindicais. As CFRs e EFAs lutam pela participação ativa na comunidade, buscando ampliar os espaços de conquista dentro do Estado; em muitos casos, os estudantes participam de mobilizações sociais de luta por reforma agrária e políticas públicas voltadas aos interesses dos agricultores.

A pedagogia do TC e do TE, que caracteriza a formação na FUNDEP e no ITERRA, sustenta-se em uma concepção/prática de pedagogia social, recorrendo aos registros das experiências pedagógicas de trabalho produtivo articulado à educação escolar efetuadas na Rússia, tendo por referência as obras de Pistrak, Makarenko e Krupskaya. Essa pedagogia que tem por base a tríade trabalho-educação-cooperação aponta para o horizonte da emancipação humana como uma conquista possível. Nessa formação a ênfase recai sobre a relação entre a educação e a realidade, a auto-organização, a disciplina e a organização de uma coletividade. Nessas experiências também podem ser observadas contradições próprias do modo capitalista de produção na qual estão mergulhadas, porque os jovens, principalmente das camadas populares, precisam de empregos para sobreviver.

Experiências históricas de educação realizadas pelos movimentos sociais populares são constantemente retomadas e recriadas para responder a novos 
desafios que emergem do contexto atual, resultando em uma fusão de novas ideias, mantendo, no entanto, a matriz original do popular. Apesar de apresentarem divergências teórico-metodológicas, as experiências pedagógicas das CFRs, da EFAs, da FUNDEP e do ITERRA têm um ponto em comum: a referência prático-teórica no educador Paulo Freire. Na sua Pedagogia do oprimido, Freire aponta a liberdade e a autonomia como possibilidades de escolha, de vida, de trabalho. Elas seriam pontos de partida. Sem negar a personalidade, própria de cada um, parte dela para ampliar a consideração das diferenças que, na base, são de classe social, mas também são de gênero, raça, cultura, idade... Enraizado nas suas vivências como educador popular, que conheceu e se envolveu com várias experiências de educação popular, em diferentes países do mundo, Paulo Freire exercita uma pedagogia emancipante como práxis que, como movimento, incorpora, reinventa e reafirma a liberdade e a emancipação.

Liberdade e autonomia, como bases de uma formação, podem apresentar limites, quando restritas à educação para o trabalho, a sobrevivência e a cidadania. Em um país capitalista, como aquele no qual vivemos e trabalhamos, estamos sujeitos a esses limites porque o trabalho, a sobrevivência e a cidadania não estão acessíveis a todos. Na perspectiva da contradição e do movimento que aponta para a superação, porém, está implícita a possibilidade de romper com as velhas relações sociais, para, por dentro delas, ir gestando as novas, assentadas sobre a cooperação em lugar da competição. A emancipação seria, nesse sentido, princípio/fim da relação entre trabalho agrícola e educação escolar.

Tendo o trabalho como princípio educativo, traços de uma concepção/prática de formação omnilateral podem ser captados nas experiências pedagógicas de trabalho-educação do movimento camponês. Tais experiências parecem integrar um projeto popular que emite alguns sinais em direção a uma sociedade diferente, em que as classes populares possam exercer a liberdade, ter autonomia em seus processos organizativos e conquistar a emancipação verdadeiramente humana. Isso é o que podemos captar nas experiências pedagógicas de trabalho agrícola e educação escolar, apesar das diferentes compreensões observadas nos princípios/fins de liberdade e emancipação que as orientam.

\section{Referências bibliográficas}

ANDREOLA, Balduino A. O processo do conhecimento em Paulo Freire. Educação e Realidade, Porto Alegre: Faced/UFRGS, v. 18, n. 1, p. 32-42, jan./jun. 1993.

BACHELARD, Paul. Apprentissage et pratiques d'alternance. Paris: L'Harmattan, 1994.

BEGNAMI, João Batista. Uma geografia da Pedagogia da Alternância no Brasil. Brasília: UNEFAB, 2004. p. 3-20. (Série Documentos Pedagógicos.)

CALDART, Roseli Salete. Oficinas de capacitação pedagógica: uma opção metodológica para a re-educação de professores. Coragem de Educar, Três Passos: FUNDEP/Departamento de Ensino Superior, n. 2, p. 19-29, nov. 1995.

. Educação em movimento. Formação de educadores e educadoras no MST. Petrópolis: Vozes, 1997.

CAPRILES, René. Makarenko: o nascimento da pedagogia socialista. São Paulo: Scipione, 1989.

CEFFAs. Preparação dos CEFFAs para o congresso. In: CONGRESSO INTERNACIONAL. FAMÍLIA, ALTERNÂNCIA E DESENVOLVIMENTO, 8., Promoção pessoal e coletiva: chave para o desenvolvimento rural sustentável, Puerto Iguazú, 2005. Anais... Puerto Iguazú: s.ed., p. 121-130. (Documento.)

CHARTIER, Daniel. A L'Aube des formations par alternance. Histoire d'une pédagogie associative dans le monde agricole et rural. Paris: UNMFREO, 1986.

.et al. Soixante ans d'histoire des Maisons Familiales

Rurales. Paris: UNMFREO, 1997.

COLETIVO DE AUTORES SOVIÉTICOS. Krupskaya, Nadiezhda Konstantinovna. Biografia. La Habana: Editorial de Ciencias Sociales, 1987.

DEWEY, John. Liberalismo, liberdade e cultura. São Paulo: Cia. Editora Nacional, 1970.

DUARTE, Newton. Vigotski e o “aprender a aprender”. Crítica às apropriações neoliberais e pós-modernas da teoria vigotskiana. 2. ed. São Paulo: Autores Associados, 2001.

DUFFAURE, André. Au-delà de l'hexagone. In: CHARTIER, Da- 
niel et al. Soixante ans d'histoire des Maisons Familiales Rurales. Paris: UNMFREO, 1997. p. 115-127.

ESTEVAM, Dimas de Oliveira. Casa Familiar Rural: a formação como base da Pedagogia da Alternância. Florianópolis: Insular, 2003.

FREIRE, Paulo. Cartas à Guiné-Bissau. Registros de uma experiência em processo. Rio de Janeiro: Paz e Terra, 1977.

. Educação como prática da liberdade. 8. ed. Rio de Janeiro: Paz e Terra, 1978.

. Ação cultural para a liberdade. 4. ed. Rio de Janeiro:

Paz e Terra, 1979.

. Pedagogia do oprimido. 9. ed. Rio de Janeiro: Paz e Terra, 1981.

. Pedagogia da autonomia. Saberes necessários à prática educativa. 20. ed. Rio de Janeiro: Paz e Terra, 2001.

Educação e participação comunitária. In:

Política e Educação. 7. ed. São Paulo: Cortez, 2003. p. 65-78.

FRIGOTTO, Gaudêncio. A dupla face do trabalho: criação e destruição da vida. In: FRIGOTTO, Gaudêncio; CIAVATTA, Maria (Orgs.). A experiência do trabalho e a educação básica. Rio de Janeiro: DP\&A, 2002. p. 11-28.

FUNDEP. Coragem de Educar, Três Passos: FUNDEP, n. 3, 32 p., nov. 1996. (Documento.)

FUNDEP. Coragem de Educar. Uma proposta de educação popular para o meio rural. 2. ed. Petrópolis: Vozes, 1995. (1. ed. 1994.)

GADOTTI, Moacir. História das idéias pedagógicas. São Paulo: Ática, 1993.

GUZMÁN, Eduardo Sevilla; MOLINA, Manuel González. Sobre a evolução do conceito de campesinato. São Paulo: Expressão Popular, 2005.

GRAMSCI, Antonio. Cadernos do Cárcere. 2. ed. v. 2 - Os intelectuais. O princípio educativo. Jornalismo. Rio de Janeiro: Civilização Brasileira, 2001.

HARVEY, David. Condição pós-moderna. 7. ed. São Paulo: Loyola, 1998.

HEGEL, Georg Wilhelm Friedrich. Princípios de filosofia do direito. Lisboa: Guimarães, 1990.

HOBSBAWM, Eric. A era dos extremos. O breve século XX (1914-1991). São Paulo: Cia das Letras, 1995.

IANNI, Octávio. Revoluções camponesas na América Latina. In: SANTOS, José Vicente Tavares dos (Org.). Revoluções camponesas na América Latina. São Paulo: Ícone; Campinas: UNICAMP, 1985. p. $15-45$.
INSTITUTO SOUZA CRUZ. Construindo conhecimentos. Projovem elabora metodologia para agricultura familiar. Marco SocialJuventude e Desenvolvimento Rural, Rio de Janeiro: Reser, v. 6, n. 1, p. 70-77, abr. 2004.

ITERRA. Método pedagógico. Cadernos do Iterra, Veranópolis, n. 9, dez. 2004.

KANT, Immanuel. O conceito de liberdade é a chave para se explicar a autonomia da vontade. In: WEFFORT, Francisco. Os clássicos da política. 7. ed. v. 2. São Paulo: Ática, 1998a. p. 99. A fórmula da autonomia. In: WEFFORT, Francisco. Os clássicos da política. 7. ed. v. 2. São Paulo: Ática, 1998b. p. 98.

LÊNIN. Sobre educação. v. I e II. Lisboa: Seara Nova, 1977.

LOCKE, John. Da propriedade. Segundo Tratado sobre o governo. In: Textos selecionados. São Paulo: Abril Cultural, 1973. p. $51-60$.

LOSURDO, Domenico. Contra-história do Liberalismo. Aparecida: Idéias \& Letras, 2006.

LUEDEMANN, Cecília da Silveira. Anton Makarenko. Vida e obra - a pedagogia na revolução. São Paulo: Expressão Popular, 2002.

MAKARENKO, Anton. Poema pedagógico en tres partes. Moscou: Progreso, s.d.

MANACORDA, Mario Alighiero. História da educação; da antiguidade aos nossos dias. São Paulo: Cortez e Autores Associados, 1989.

MARTINS, José de Souza. Caminhada no chão da noite. Emancipação política e libertação nos movimentos sociais do campo. São Paulo: Hucitec, 1989.

MARX, Karl. Las luchas de clases en Francia de 1848 a 1850. Moscou: Progreso, 1979.

O capital. Livro 1. v. I e II. 8. ed. São Paulo: Difel, 1982.

Formações econômicas pré-capitalistas. 4. ed. Rio de Janeiro: Paz e Terra, 1985.

. A guerra civil na França. São Paulo: Global, 1986. .; ENGELS, Friedrich. A ideologia alemã. Teses sobre

Feuerbach. São Paulo: Moraes, 1984.

MELO, João A. Telles (Org.). Reforma agrária quando? CPI mostra as causas da luta pela terra no Brasil. Brasília: Gráfica do Senado, 2006.

MILL, John Stuart. Sobre a liberdade. Cap. 1. Introdução. Textos de Stuart Mill. In: WEFFORT, Francisco. Os clássicos da política. 
7. ed. v. 2. São Paulo: Ática, 1998. p. 200-210.

MORIN, Edgar. Introdução ao pensamento complexo. Lisboa: Instituto Piaget, 1990.

- A cabeça bem feita. Repensar a reforma, reformar o pensamento. 8. ed. Rio de Janeiro: Bertrand Brasil, 2003.

MST - Movimento dos Trabalhadores Rural Sem Terra. Princípio da Educação no MST. Edição especial. Dossiê MST Escola. Documentos e Estudos - 1990-2001. Caderno de Educação, São Paulo: Iterra, n. 13, ago. 2005.

. Memória cronológica. Cadernos do Iterra, Veranópolis: Iterra, n. 1, maio 2001.

PAIVA, Vanilda (Org.). Perspectivas e dilemas da educação popular. Rio de Janeiro: Graal, 1984.

PALUDO, Conceição. Educação popular em busca de alternativas. Porto Alegre: CAMP/Tomo Editorial, 2001.

PIAGET, Jean. A epistemologia genética. Sabedoria e ilusões da filosofia. Os Pensadores (LI). São Paulo: Abril Cultural, 1975.

Para onde vai a educação? 4. ed. Rio de Janeiro:

Livraria José Olympio, 1976a.

. Psicologia e pedagogia. 4. ed. Rio de Janeiro: Forense

Universitária, 1976b.

PISTRAK. Fundamentos da Escola do Trabalho. São Paulo: Brasiliense, 1981.

POLANYI, Karl. A grande transformação. Rio de Janeiro: Campus, 2000.

RIBEIRO, Marlene. A originalidade de Paulo Freire no pensamento educacional brasileiro. Educação em Revista, Belo Horizonte: FAE/ UFMG, n. 29, p. 15-30, jun. 1999.

. Educação para a cidadania: questão colocada pelos movimentos sociais. In: Educação e Pesquisa, São Paulo: FAE/ USP, v. 28, n. 2, p. 113-128, jul./dez. 2002.

. Pedagogia da Alternância na educação rural/do campo: projetos em disputa. Educação e Pesquisa, São Paulo: FAE/ USP, v. 34, n. 1, p. 27-46, jan./abr. 2008.

. Movimentos sociais e políticas públicas, no Brasil: práticas/concepções de educação em conflito. 2009. 15 p. Artigo Inédito. Encaminhado à publicação de obra resultante do III Sim- pósio Luso-Brasileiro, Lisboa, 2009.

ROSSI, Wagner Gonçalves. Pedagogia do Trabalho. Caminhos da educação socialista. v. 2. São Paulo: Moraes, 1982.

ROUSSEAU, Jean Jacques. Do contrato social. Textos escolhidos. São Paulo: Abril Cultural, 1973. p. 21-152. (Col. Os Pensadores, v. XXIV.)

SILVA, Lourdes Helena da. As experiências de formação de jovens do campo: alternância ou alternâncias? Viçosa: Ed. UFV, 2003. SILVA, Tomaz Tadeu. As pedagogias psi e o governo do eu nos regimes neoliberais. $I n$ : (Org.). Liberdades reguladas. A pedagogia construtivista e outras formas de governo do eu. Petrópolis: Vozes, 1998. p. 7-13.

SOUZA, João Francisco de. Educação popular e movimentos sociais no Brasil. In: CANÁRIO, Rui (Org.). Educação popular \& movimentos sociais. Lisboa: Educa, 2007. p. 37-80.

SOUZA SANTOS, Boaventura de. Pela Mão de Alice. O social e o político na pós-modernidade. 3. ed. Porto: Afrontamento, 1994. TRAGTEMBERG, Maurício. Pistrak: uma pedagogia socialista. In: PISTRAK. Fundamentos da Escola do Trabalho. São Paulo: Brasiliense, 1981. p. 7-24.

MARLENE RIBEIRO, doutora em educação pela Universidade Federal do Rio Grande do Sul (UFRGS, 1995), com pós-doutorado na Universidade do Estado do Rio de Janeiro (UERJ, 2008), está vinculada ao curso de pedagogia e ao Programa de Pós-Graduação em Educação da UFRGS. Publicações recentes: Pedagogia da Alternância na educação rural/do campo: projetos em disputa (Educação e Pesquisa, São Paulo: Universidade de São Paulo, v. 34, p. 27-47, 2008); Educação popular: um projeto coletivo dos movimentos sociais populares (Perspectiva, Florianópolis, v. 26, p. 41-68, 2008); O cooperativismo na formação do técnico agrícola: contradições da cooperativa-escola (Cadernos de Educação, Pelotas: UFPel, v. 28, p. 85-118, jan./jun. 2007). Pesquisa em andamento, com bolsa de produtividade do Conselho Nacional de Desenvolvimento Científico e Tecnológico (CNPq): “Experiências pedagógicas dos movimentos sociais populares e políticas de educação rural/do campo: confronto de concepções” (2008-2011).E-mail: maribe@adufrgs.ufrgs.br 
Key words: Bologna Process; Europe; higher education; regionalization; globalization.

\section{El proceso de Bolonia se vuelve} global: modelo, mercado, movilidad, fuerza intelectual, $\dot{c}$ estrategia para la construcción del Estado?

El artículo examina la interconexión progresiva de los espacios de la politica de educación superior, enfocando particularmente a Europa y a su proyecto de globalización de la educación superior, así como las implicaciones del mismo para otras economías nacionales y regionales. El trabajo comienza con el Espacio Europeo de Educación Superior, delineando las principales características del competitivo proyecto europeo en la educación superior. Presentándose como el Proyecto Multilateral de Bolonia, proyectado para crear una arquitectura unificada de educación superior en Europa, fue remodelado y dirigido por la estrategia Lisboa 2000 de la Unión Europea para la competitividad y por el relanzamiento de la Agenda Lisboa 2005. Esta agenda ha permitido la utilización de la educación superior como una plataforma para amplias estrategias de regionalización y globalización de la Unión Europea, para crear tanto "mentes" cuanto "mercados" para la economía europea de conocimiento, llevando a la emergencia de un sistema global más integrado y relacional de educación superior. Las acciones de Europa también son moldeadas por su propio proyecto de construcción del Estado, que tiende a favorecer a la colaboración con las regiones y promover el inter regionalismo como una plataforma para la negociación global.

Palabras claves: Proceso de Bolonia; Europa; educación superior; regionalización; globalización.
Marlene Ribeiro

Trabalho e educação no movimento camponês: liberdade ou emancipação?

O artigo aborda o tema "trabalho, movimentos sociais e educação”. Tem por objetivo trazer elementos para identificar os princípios/fins de liberdade e emancipação que sustentam as experiências de trabalho-educação em sistema de alternância, realizadas pelos movimentos sociais populares do campo. Trata-se das organizações sindicais de trabalhadores rurais e dos movimentos organizados da Via Campesina. Apesar da diversidade de sujeitos, projetos sociais e formas de organização, esses movimentos têm em comum uma luta histórica pela terra de trabalho e pela democracia, o que permite sintetizá-los na unidade movimento camponês. Na importância do estudo destaca-se a necessidade de atentarmos para o novo contido nas experiências de trabalho-educação do movimento camponês, que são produzidas à revelia do processo de reprodução e acumulação do capital e do controle do Estado.

Palavras-chave: trabalho-educação; movimentos sociais; pedagogia da alternância; liberdade e emancipação.

\section{Work and education in the Rural Workers' Movement: freedom or emancipation?}

The article is about work, social movements and education. Its objective is to present elements in order to attempt to identify the principles and ends of freedom and emancipation which sustain experiences of workeducation in a system of alternation, carried out by popular social movements in the countryside. It deals with trade union organizations of rural workers and the movements organized by the Via Campesina. Despite the diversity of subjects, social projects and types of organization, these movements have in common an historical struggle for land on which to work and for democracy, which allow us to synthesize them in the one unit of Rural Workers'Movement. The study is important in that it highlights the need to pay attention to what is new in the experiences of work-education developed by the Rural Workers' Movement, which is produced in the absence of the process of reproduction and accumulation of capital and of State control.

Key words: work-education; social movements; pedagogy of alternation; liberty and emancipation.

¿Trabajo y educación en el movimiento campesino: libertad o emancipación?

El artículo trata del tema "trabajo, movimientos sociales y educación”. Tiene por objetivo traer elementos para identificar los principios y los fines de libertad y emancipación que sostienen las experiencias de trabajo-educación en sistema de alternancia, realizadas por los movimientos sociales populares del campo. Se trata de las organizaciones sindicales de trabajadores rurales $y$ de los movimientos organizados de la Vía Campesina. A pesar de la diversidad de sujetos, proyectos sociales y formas de organización estos movimientos tienen en común una lucha histórica por la tierra de trabajo y por la democracia, lo que nos permite sintetizarlos en la unidad movimiento campesino. En la importancia del estudio se destaca la necesidad de considerar acerca del nuevo contenido en las experiencias de trabajo-educación del movimiento campesino, que son producidas en oposición del proceso de reproducción y de acumulación del capital y del control del Estado.

Palabras claves: trabajo-educación; 
movimientos sociales; pedagogía de la alternancia; libertad y emancipación.

André Luiz Paulilo

As estratégias de administração das políticas públicas de educação na cidade do Rio de Janeiro entre 1922 e 1935

$\mathrm{O}$ artigo busca explanar as estratégias de administração da educação pública desenvolvidas na cidade do Rio de Janeiro entre 1922 e 1935. Examinando as políticas públicas de educação, durante as administrações de Antônio Carneiro Leão (1922-1926), Fernando de Azevedo (1927-1930) e Anísio Teixeira (1931-1935), apresenta as mudanças ocorridas na organização da Diretoria Geral de Instrução Pública. Na complexa rede de instituições e saberes, visando reformar a estrutura administrativa da educação, a ampliação das agências de Estado e a especialização dos serviços de educação constituem um importante recurso político.

Palavras-chave: políticas públicas de educação; reforma educacional; escolarização 1922-1935; história da educação.

\section{The administrative strategies for public policies of education in the city of Rio de escolaridad 1922-1935; historia de la educación.} Janeiro between 1922 and 1935

This article seeks to explain the administrative strategies for public education developed in the city of Rio de Janeiro between 1922 and 1935. A careful look at the public policies of education, during the administrations of Antônio Carneiro Leão (1922-1926), Fernando de Azevedo (1927-1930) and Anisio Teixeira (1931-1935), shows the changes in the organization of the General Directorate of Public Instruction in the Federal District. The amplification of state agencies and the specialization of educational services constitute an important political resource in the complex network of institutions and knowledge, aimed at reforming the administrative structure of education.
Key words: public policies of education; educational reform; schooling 19221935; history of education.

Las estrategias de administración de las políticas públicas de educación en la ciudad de Rio de Janeiro entre 1922 y 1935

El artículo busca explicar las estrategias de administración de la educación pública desarrolladas en la ciudad de Rio de Janeiro entre 1922 y 1935. Examinando las politicas públicas de educación, durante la administración de Antônio Carneiro Leão (1922-1926), Fernando de Azevedo (1927-1930) y Anísio Teixeira (1931-1935), presenta los cambios ocurridos en la organización de la Directoria General de Instrucción Pública. En la compleja red de instituciones y saber, enfocando la reforma de la estructura administrativa de la educación, la ampliación de las agencias de Estado y la especialización de los servicios de educación constituyen un importante recurso político.

Palabras claves: políticas públicas de educación; reforma educacional;

Menga Lüdke, Giseli Barreto da Cruz e Luiz Alberto Boing

A pesquisa do professor da educação básica em análise

O texto discute a pesquisa do professor com autores que veem nela alguma possibilidade de acontecer. Dentre os autores trabalhados, destacam-se: Stenhouse, Elliott, Huberman, Geraldi, Fiorentini, Cochran-Smith, Lytle, Anderson, Herr, André, Lüdke, Cruz, Zeichner, Diniz-Pereira, Nofke, Tardif e Zourhlal. Para servir de instrumento à pesquisa, foram selecionados dois trabalhos de professores que foram apresentados no XII Encontro Nacional de Didática e Prática de Ensino (ENDIPE,
2004) e dois outros no II Seminário Internacional de Pesquisa em Educação Matemática (SIPEM, 2003). Os quatro textos foram enviados a 12 juízes, escolhidos em diferentes instâncias, dentre profissionais bem preparados em suas respectivas áreas de formação, com vasta experiência de pesquisa e intensa produção, além de interessados e sensibilizados com a formação de professores, inclusive no que se refere à sua pesquisa. A partir dos pareceres desses avaliadores, são apresentados alguns resultados teórico-metodológicos e práticos que podem enriquecer o debate sobre os limites e possibilidades da pesquisa dos professores.

Palavras-chave: pesquisa educacional; professor da educação básica; julgamento.

\section{Primary school teacher research under appraisal}

The text discusses teacher research with writers who perceive the possibility of this kind of research taking place. Among these writers we highlight: Stenhouse, Elliott, Huberman, Geraldi, Fiorentini, Cochran-Smith, Lytle, Anderson, Herr, André, Lüdke, Cruz, Zeichner, Diniz-Pereira, Nofke, Tardif e Zourhlal. As research tools, two papers presented by teachers at the XII Encontro Nacional de Didática e Prática de Ensino (ENDIPE, 2004) and two other papers presented at the II Seminário Internacional de Pesquisa em Educação Matemática (SIPEM, 2003) were selected. The four texts were sent to twelve judges chosen at different instances among well-reputed professionals in their respective areas of expertise, with considerable research experience and impressive academic production. The selected judges had also shown interest and understanding of teacher training, including teacher research. Based on the written views of these evaluators some theoreticalmethodological as well as practical results are presented that might 